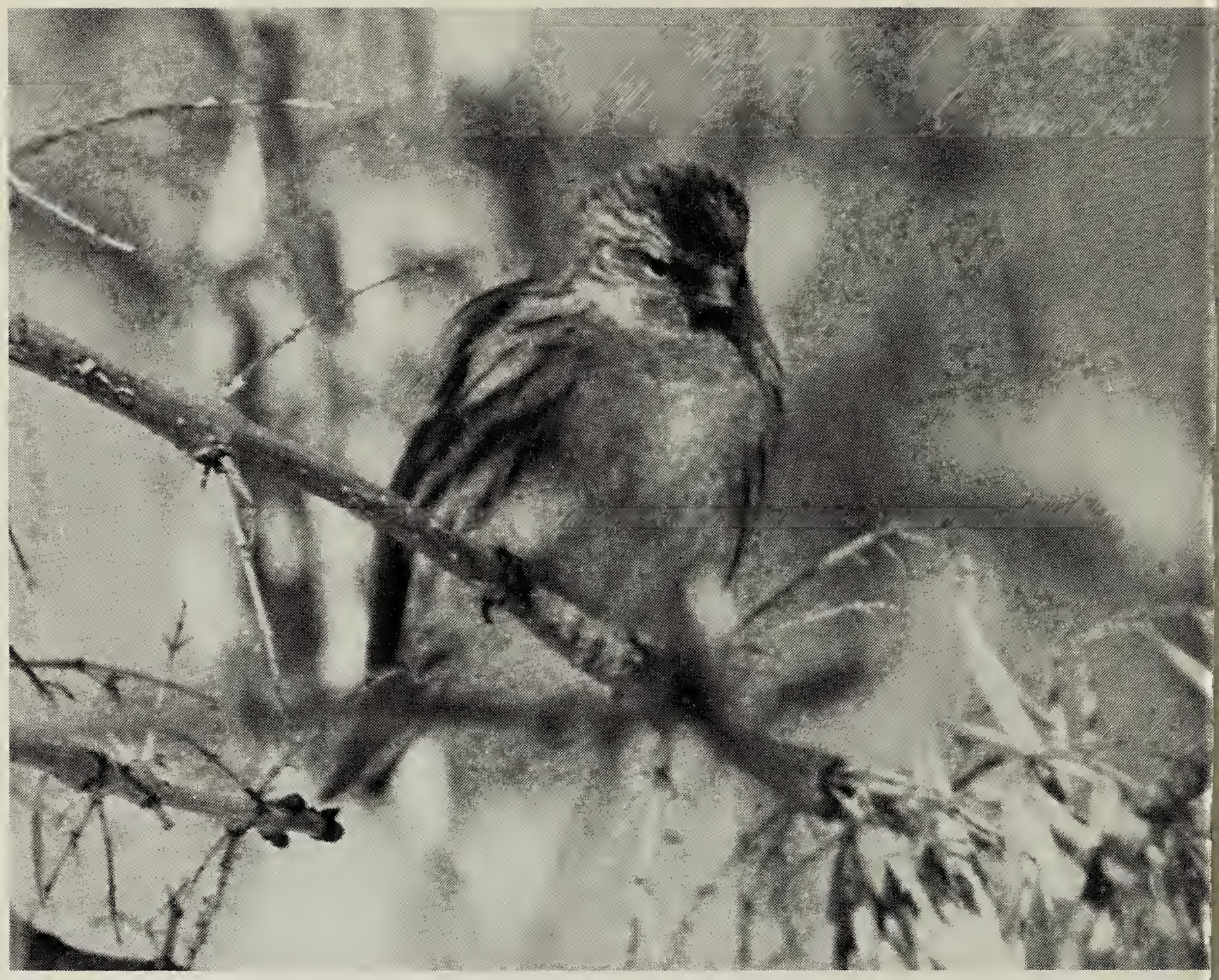

Common redpoll

Fred W. Lahrr

\section{EARLY RECORD OF REDPOLL NESTING IN SOUTHERN ALBERTA}

MARTIN K. MC NICHOLL, Department of Biological Sciences,

Brock University, St. Catharines, Ontario L2S 3A1

Recently Lister and Godfrey have documented the nesting of Common Redpolls in Alberta.' 2 Godfrey expressed the opinion that nesting of this species in southern Alberta and Saskatchewan is more likely an overlooked situation of long standing than a recent development. ${ }^{2}$ Recently while compiling a bibliography of Alberta birds, I found an untitled note by C. H. Snell which supports Godfrey's view, at least to the extent that such southern breeding records are not infrequent. ${ }^{3}$ On May 19, 1924 Sn observed a female Common Redp feeding three young at Red De Alberta. Snell's identification appe not to have been confirmed, but description of the female's black cl patch and dull red cap leaves lit doubt as to its accuracy. This recorc further south in Alberta than any of $t$ records mentioned by Lister Godfrey, and also almost two decac earlier. ${ }^{12}$

'GODFREY, W. E. 1976. Breeding status the Common Redpoll in Alberta Saskatchewan. Canadian Field $-\Lambda$ 90:199-200.

${ }^{2}$ LISTER, R. 1975. Common Redpolls nest at Edmonton, Alberta. Canadian $\mathrm{Fi}$ Nat. 89:64-65.

${ }^{3}$ SNELL, C. H. 1926. (untitled no Canadian Field Nat. 40:18. 